\title{
The Influence of Opening Statement/Closing Argument Organizational Strategy on Juror Verdict and Damage Awards ${ }^{1}$
}

\author{
Shelley C. Spiecker ${ }^{2}$ and Debra L. Worthington ${ }^{3,4}$
}

This study examines the influence of the organizational strategy used to structure opening statements and closing arguments on presentation effectiveness in a simulated civil trial. Two organizational structures, a narrative and a legal-expository format, were manipulated to produce a 2 (plaintiff organizational strategy) $\times 3$ (defense organizational strategy) experimental design. Results indicate that a mixed organizational strategy (narrative opening/legal-expository closing) is more effective for the plaintiff than a strict narrative strategy, and either a mixed or strict legal-expository organizational strategy is more effective than a strict narrative strategy for the defense.

KEY WORDS: opening statements; closing arguments; organization; verdict formation; damage awards; juror decision making.

\section{INTRODUCTION}

Legal communication scholars recognize the importance of opening statements and closing arguments in juror decision-making (see, for example, Matlon, 1988, 1993; Rieke \& Stutman, 1990). Some attorneys, such as Connolly (1982), feel lawsuits are won in the opening statement. Although others are not as deterministic, most agree, and research demonstrates the opening statement is important because it creates a schema or "framework" through which jurors filter the subsequent presentation of evidence (Moore, 1989; Pyszczynski \& Wrightsman, 1981).

Just as opening statements are influential in their ability to frame a dispute, closing arguments are influential in their ability to synthesize trial information and remind jurors of evidence deemed important to an advocate's case (Matlon, 1993).

\footnotetext{
${ }^{1}$ Paper presented to the Commission on Communication and Law at the 2002 National Communication Association, New Orleans, LA, USA.

${ }^{2}$ Persuasion Strategies, Denver, Colorado.

${ }^{3}$ Department of Communication and Journalism, Auburn University, Auburn, Alabama.

${ }^{4}$ To whom correspondence should be addressed at Department of Communication and Journalism, 217 Tichenor Hall, Auburn University, Auburn, Alabama, 36849; e-mail: worthdl@auburn.edu.
} 
Although the primary purpose of a closing argument is to assist jurors in analyzing the trial evidence in order to reach a "just and reasonable conclusion based on the evidence alone," in actuality, attorneys view closings as their final opportunity to convince the jury, matching the evidence and the law in such a way that they, and their clients, win the case (Montz, 2001). This interpretation process applies not only to evidence presented in the advocate's case-in-chief but in the opposition's case as well.

One issue that attorneys must address when formulating their opening and closing statements is how to organize the presentation, (e.g., narrative, expository, deconstruction, etc.). In opening statements, organizational structure can influence the schema jurors use to interpret the subsequent evidence and information presented during the trial. In closing arguments, organizational structure can assist advocates in synthesizing information for jurors and interpreting evidence in a manner consistent with the advocate's case theory.

Although other studies have examined the impact of the organizational structure of witness testimony (Devine \& Ostrom, 1985; Pennington \& Hastie, 1988, 1992), in actual trial practice advocates have little latitude in selecting and implementing its organizational structure. Given that opening statements and closing arguments afford attorneys the greatest freedom to structure their communication, it is both theoretically and pragmatically important to investigate the influence of organizational structure. Therefore, this study examines the influence of opening statement and closing argument organizational structure on jurors' verdicts and damage awards.

\section{TYPES OF ORGANIZATIONAL STRUCTURES}

\section{Narrative Format}

It is not unusual for opening statements and closing arguments to take on a narrative form (Voss \& Van Dyke, 2001). Although legal scholars have noted with concern the "faddish" reliance of some trial advocates on the narrative approach (Kadoch, 2000, p. 82), the fact is that attorneys, law schools, law journals, legal trade publications, trial advocacy texts, and psycholegal scholars have sung the praises of the storytelling technique (Herman, 1993; Larson, 2000; Lempert, 1991; Lubet, 1993; Manzo, 1994; Mauet, 1992; Ogborn, 1995; Ohlbaum, 1993; Oliver, 1994; Powell, 2001; Sherwin, 1994; Spence, 1995). Story structure in legal argument, as described by Pennington and Hastie (1981), consists of a series of interrelated episodes. Each episode is composed of five parts: initiating events; goals; actions; consequences; and accompanying states. In a complete story, all five episode elements are present and are introduced in the natural temporal order in which they occurred. Although other researchers of legal argument provide slightly different descriptions of narrative structure (Bennett \& Feldman, 1981; Jackson, 1991; Miller, 1994), the basic components are essentially the same.

There is a large body of empirical literature supporting the superiority of the narrative structure in a variety of areas including comprehension and memory (e.g., Cohen \& Graesser, 1980; Mandler, 1984; Mandler \& Johnson, 1977; Stein \& Trabasso, 1982; Trabasso, van den Broek, \& Suh, 1989). For example, Mandler (1984) and Mandler and Johnson (1977) found that story schema is so natural to message 
recipients that even when information is not presented in standard story form, receivers reorder the information in their recall so that it is consistent with an episodic or story structure. Discourse processing researchers theorize that the story structure facilitates comprehension and recall because it facilitates causal analysis. In other words, understanding a story involves understanding the causes and effects of the events it describes. The temporality of the story structure is what allows for causal reasoning, leading receivers more readily to identify goals, plans, and actions (Bower, Black, \& Turner, 1979; Graesser, 1981). Mandler (1984) takes the causal reasoning explanation a step further, arguing that story structure aids information processing because it organizes information not only vertically but horizontally as well. In other words, information within each "tree," or level, is interrelated, as well as related to information above and below it on the hierarchy. This cross-referenced system of relationships provides receivers with multiple cues for organizing, storing, and retrieving information. Mandler (1984) argues that all receivers possess this inherent "story schema," facilitating the comprehension of information presented in a narrative format.

A series of studies by Pennington and Hastie (1981, 1986, 1988, 1992) demonstrated the importance of story telling to jury decision-making. Although Pennington and Hastie did not examine the effect of organizational structure in opening statements and closing arguments, two studies conducted as part of their research program examined the role of the organizational structure of evidence presentation (Pennington \& Hastie, 1988, 1992). Similary, Smith $(1991,1993)$ has examined the effect of jurors' prototypes and prior knowledge on jurors' decision-making. In total, their research indicates that jurors' stories can mediate their decisions, influence their perceptions of evidence, and affect confidence in their decisions. Jurors' stories become even more important when jurors begin to attempt to match their personal stories against the possible verdicts presented by the presiding judge. However, although the research by Pennington and Hastie, Smith, and others compose a rich body of research examining the role of story formation in juror decision-making, little has directly addressed the focus of this study - the effect of the structure of the attorneys' opening and closings on juror decision-making.

\section{Other Identified Formats}

Kadoch (2000) argues that the law and the legal system itself encourage lawyers to use narrative when presenting their cases to juries, a technique that may actually be inappropriate at times. Certainly, legal trade publications and advocacy texts have popularized the narrative organizational style of information presentation. However, social scientific and legal scholars as well as practitioners note the viability and use of other types of organizational strategies (Bennett \& Feldman, 1981; Schum, 1993; Sherwin, 1994). For example, examination of organization formats employed in criminal suits found that defense attorneys utilize at least three other types of strategies. First, they may choose strategies involving challenging or deconstructing the prosecution's story (Bennett \& Feldman, 1981; Sherwin, 1994). A second strategy involves redefinition, where the defense reinterprets aspects of the prosecution's story (Bennett \& Feldman, 1981). In a third strategy, attorneys utilize what Sherwin 
(1994) termed a legal strategy, emphasizing the verdict attributes that must be met in order to reach a specific decision and that structures information around the judicial instructions and burden of proof.

Within the civil context, Schum (1993) describes two forms of "argument structuring" employed by advocates: temporal and relational structuring. Corresponding to the storytelling technique, temporal structuring places emphasis on ordering events significant to the dispute in chronological order. Relational structuring places emphasis on "the manner in which evidence items bear on particular issues" and shows how evidence items are related to each other and to major facts in issue (p. 189). This organizational structure resembles a point-counterpoint presentation or legal expository structure. The legal-expository structure is identified by the delineation of the judicial instructions and legal elements governing the dispute, accompanied by a preview in the opening statement or summary in the closing argument of why the evidence in the case either supports or refutes the applicable law.

Both within and outside the legal field it is clear there is more than one way to organize and present information. Although narrative organization is currently endorsed by many as a superior organizational structure, research addressing this perspective and the role of organizational structure on juror decisions is needed.

\section{POTENTIAL EFFECTS OF ORGANIZATIONAL STRUCTURE}

Despite the implications of organizational structure in opening and closing statements, only one study has directly tested its effects. McCullough (1991) manipulated two types of organizational structures, a narrative structure and a comparisonexpository structure. The narrative structure was defined as a "story" containing an "exposition, complication and resolution" where the actors and situation were introduced in the exposition, followed by an event that required action by the actors in the complication, and concluding with the resolution returning the story to a new stable state (pp. 10,17). The comparison-expository structure was defined as an organization based on the "similarities and differences" of information, "such as when two opposing views are compared on the same issue(s)" (p. 11). When operationalizing the comparison-expository structure, McCullough contrasted the plaintiff's and defendant's arguments point by point. A third type of presentation McCullough labeled as "rhetorical" was also included and was void of either a narrative or comparison-expository structure. For the opening, this strategy consisted of a one paragraph summary of neutral case facts, whereas the closing argument was a one paragraph summary essentially thanking jurors for their attention and listing the evidence favoring the advocate's case theory. The four conditions comprising McCullough's design were (1) both plaintiff and defense open narratively, both close rhetorically; (2) plaintiff opens narratively/defense opens comparative-expository, both close rhetorically; (3) both plaintiff and defense open rhetorically and both close narratively; and (4) both plaintiff and defense open rhetorically, defense closes comparative-expository/plaintiff closes narratively.

McCullough found the comparison-expository structure more effective than a narrative structure for the defense's closing argument. McCullough suggested that 
a narrative opening may be most effective because it cues jurors to organize subsequent evidence according to a story schema; yet a comparison-expository structure is more effective for the defense's closing argument because it explicitly challenges the plaintiff's claims. McCullough's results support the prediction that the organizational structure of opening statements and closing arguments influences juror decisionmaking. However, the study did not test the effect of a strictly narrative or strictly comparison-expository presentation (i.e., a defense opening statement and closing argument exhibiting the same organizational structure), nor did it fully explore the organizational structure of the plaintiff's opening statement and closing argument. Specifically, the plaintiff's opening and closing were presented only in rhetorical or narrative form. Thus, the effects of the legal expository organization, arguably a common format for closing arguments, were not tested.

In addition, a structure such as McCullough's comparison-expository pattern omits typical story elements such as a setting and goal-motivated behavior, making such structures appear more like incomplete than complete stories (McCullough, 1991). Research from discourse processing on the effect of story completeness indicates that receivers who receive a "complete" story (containing all the structural elements of setting, episode, etc.) rate the story more informative and comprehensible than a story missing one or more constituent elements (Brewer \& Liechtenstein, 1981; Stein \& Policastro, 1984). Although a comparison-expository or legal-expository organizational format may contain the same constituent elements as a complete story, they are often not presented in a standard temporal order, but in a topical, issuerelated order. Temporal stories generally have higher recall ratings (Mandler, 1984; Stein \& Trabasso, 1982). Thus, when one advocate uses a narrative structure and the other a legal-expository structure, the narratively-organized presentation may be more effective because it is seen as more complete than the opposing advocate's presentation. Likewise, a legal-expository structure, which is persuasive when juxtaposed to a similarly structured presentation, may become less effective when juxtaposed to a narratively organized presentation.

\section{HYPOTHESIS}

The purpose of this investigation is to explore the effects of opening statement and closing argument organizational structure on juror decision-making. Based on the following review, the following hypothesis is proposed: A narrative opening statement combined with a legal-expository closing argument will be the most effective presentation strategy for both the plaintiff and defense.

\section{EXPERIMENTAL METHODS AND PROCEDURES}

\section{Subjects}

Ranging in age from 18 to 52 (mean =19.94), 149 women and 97 men enrolled in introductory communication courses at a large midwestern university volunteered for the study and received extra credit for their participation. 


\section{Experimental Design}

To test the hypotheses and research questions a 2 (plaintiff organizational strategy) $\times 3$ (defense organizational strategy) experimental design was utilized, manipulating the organizational structure of the plaintiff's and defense's opening statements and closing arguments in a simulated civil trial to create the various organizational strategies. The five organizational strategies and six experimental conditions are presented in Table 1. Within each condition, all presentations and measuring instruments were held constant; only the structure of the opening statements and closing arguments varied.

\section{Explanation of the Manipulated Organizational Strategies}

Two organizational structures labeled a "narrative" and a "legal-expository" were manipulated in various combinations in plaintiff and defense opening statements and closing arguments to produce a total of five different organizational strategies. The narrative organizational structure embodies those structural elements identified in the literature as typifying narrative discourse-description of a setting establishing the context for the disputed situation, depiction of a series of interrelated episodes consisting of action sequences, description of the main character in the story, and temporal organization.

The legal-expository structure represents a type of organizational structure identified by a variety of terms (e.g., rule-element, relational structuring, legal strategy, etc.) as a frequently-employed type of legal argument (Feigenson, 1995; Schum, 1993; Sherwin, 1994). Information is presented in a point-counterpoint comparative style. This format includes the legal elements, which comprise the governing law, and emphasizes the applicable judicial instructions and burden of proof governing the case. In addition, in the legal-expository structure condition, each legal element of the plaintiff's required proof is delineated. When the plaintiff uses this legal-expository structure, delineation of each legal element is followed by a paragraph summary warranting acceptance of the element. When used by the defense, delineation of each legal element is followed by a paragraph summary refuting the element. Additionally, applicable legal terminology and the import of the burden of proof are presented.

Five total organizational strategies were operationalized: (1) a strict plaintiff narrative strategy with the plaintiff's opening statement and closing argument organized narratively; (2) a strict defense narrative strategy with the defense's opening statement and closing argument organized narratively; (3) a strict defense legal-expository strategy with the defense's opening statement and closing argument organized in a legal-expository format; (4) a plaintiff mixed strategy with a narrative opening statement and legal-expository closing argument; and (5) a defense mixed strategy with a narrative opening statement and legal-expository closing.

This typology omits three possible organizational strategies-a plaintiff's strict legal-expository strategy and plaintiff and defense mixed strategies with legalexpository opening statements and narrative closing arguments. The plaintiff's strict narrative strategy was omitted over the defense strict narrative strategy because the latter is similar to a "strict defense," a recognized defense strategy in trial advocacy. Because defense attorneys do not have the burden of proof, at times it is strategic 


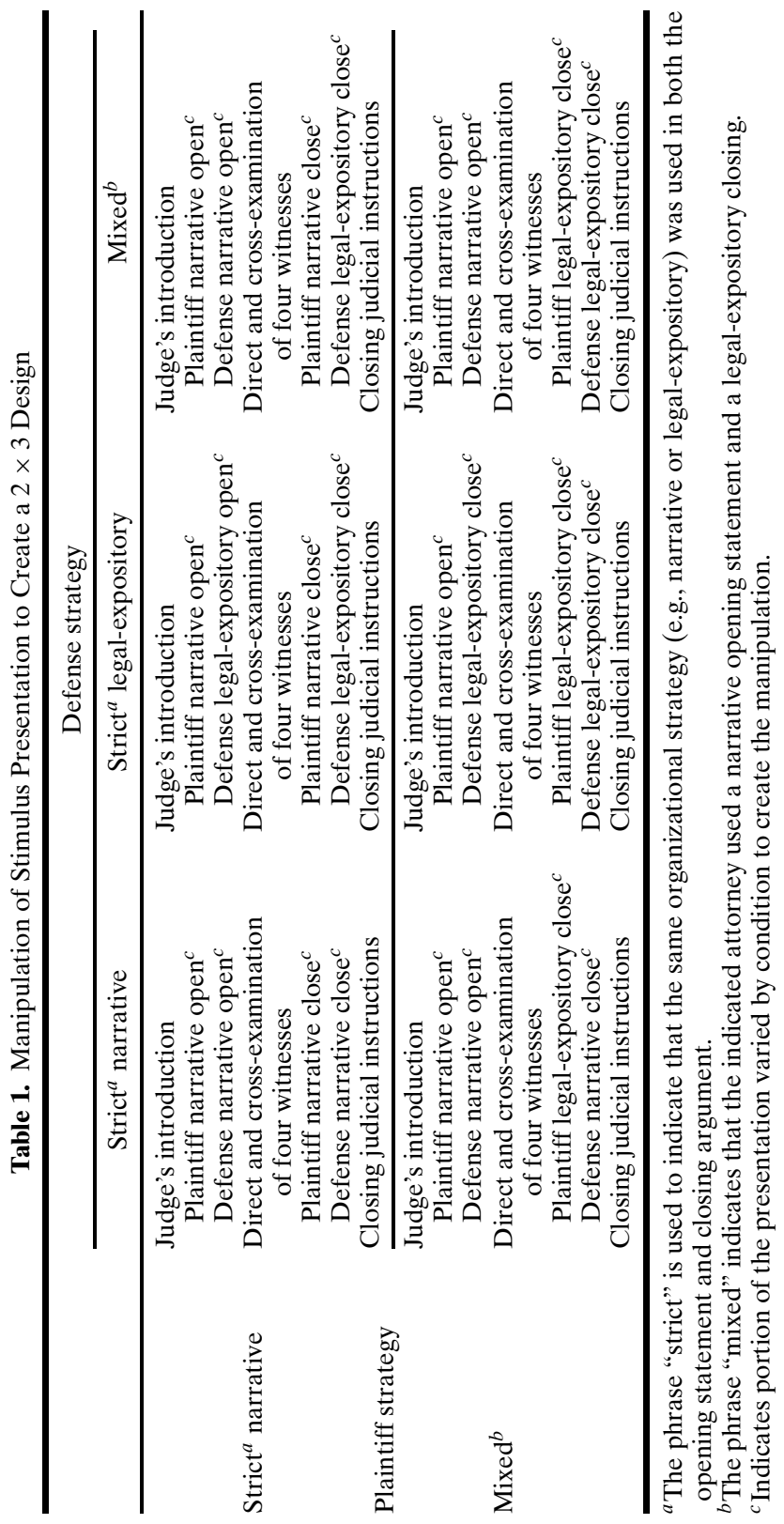


for them to use both opening statements and closing arguments simply to refute the plaintiff's claims rather than constructively create an alternative narrative explaining the disputed event. Although this strategy may be used by the defense, there is no analogous trial strategy for the plaintiff similar to a strict defense strategy.

Investigation of a mixed organizational strategy with a legal-expository opening and narrative close for the plaintiff and defense was chosen for omission for a similar pragmatic reason. Communication theorists advise attorneys to present opening statements narratively and closing arguments in a legal-expository type format, not vice versa (see, for example, Matlon, 1988). Finally, it is prudent initially to examine those strategies that practice suggests are most prevalent, allocating resources to experimental conditions representative of "real-world" practice.

\section{Stimulus Material}

Six videotapes were filmed with actors role-playing a plaintiff and defense attorney, judge, and four witnesses in the case. The scripts for the stimulus materials were created from the case file Vending Operator Incorporated v. Nita Department of Transportation, produced by the National Institute of Trial Advocacy (Lubet, 1989). ${ }^{5}$ All stimulus materials were filmed in a courtroom with the same actors portraying the roles of the attorneys, judge, and witnesses.

The case centers on a dispute over a purported breach of contract. The plaintiff contracted to establish and maintain vending facilities at state rest stops in Idaho. The contract stipulated the plaintiff would install and operate 12 vending sites for an initial 2-year period. If the sites were successful, the plaintiff could install and operate as many vending sites at the state's 90 rest stops as the plaintiff saw fit over the next 5year period. The state was to receive $2 \%$ of the plaintiff's gross sales for the first 2 years and $3 \%$ of gross sales in the remaining 5 years. Twenty months after the plaintiff began the vending operation, the defendant claimed the plaintiff failed to meet the terms of the contract and canceled the agreement, confiscating the 12 vending stations. The plaintiff sued the defendant for breach of contract. Liability rested on the law of comparative negligence and responsibility as apportioned between the parties.

Two witnesses, the president and operations manager of the vending company, testified for the plaintiff. The director and property manager for the Idaho State Department of Transportation (DOT) testified for the defendant. As stated previously, only the organizational structure of the plaintiff and defense's opening statements and closing arguments was manipulated. A brief synopsis of the opening and closing presentations are presented below and the narrative openings are more fully outlined in Table 2.

The plaintiff attorney's narratively-structured opening statement began by thanking the "jurors" for their participation, followed by a statement that to best understand the case it is important to know the story of what happened in the dispute. This narrative opening included a description of the setting for the dispute (e.g., location of the vending machines, background information about the contract, and time span of the dispute), a chronological account of the events or episodes pertaining

\footnotetext{
${ }^{5}$ The case file provides the basic case facts, witness profiles and depositions, applicable judicial instructions, and descriptions of demonstrative evidence, such as contracts and diagrams of vending locations.
} 
Table 2. Brief Summary of Defense and Plaintiff Narrative Openings

\begin{tabular}{|c|c|}
\hline Plaintiff narrative opening & Defense narrative opening \\
\hline $\begin{array}{l}\text { Vending Operations (VO) was awarded the } \\
\text { state bid. }\end{array}$ & $\begin{array}{l}\text { Motorist demand led the Idaho Department } \\
\text { of Transportation (DOT) to subcontract } \\
\text { vender services at the state's rest stops. }\end{array}$ \\
\hline $\begin{array}{l}\text { VO chose to spread the vending sites across } \\
\text { the state to maximize motorist exposure } \\
\text { and subsequent purchases. }\end{array}$ & $\begin{array}{l}\text { VO was chosen because of revenue } \\
\text { projections and higher royalty payments. } \\
\text { The initial contract was for a 2-year trial } \\
\text { period. The contract allowed VO to } \\
\text { expand its business in a constricted } \\
\text { marketplace. }\end{array}$ \\
\hline $\begin{array}{l}\text { VO drivers serviced the sites including } \\
\text { cleaning. VO claims cleaning was the } \\
\text { State's responsibility. VO did it to ensure } \\
\text { project success. VO planned to add drivers } \\
\text { at the end of the initial 2-year trial period. }\end{array}$ & $\begin{array}{l}\text { VO placed machines across the state. Some } \\
\text { DOT officials worried that the distance } \\
\text { between locations could affect servicing of } \\
\text { the sites. }\end{array}$ \\
\hline $\begin{array}{l}\text { VO cleaned for } 6 \text { months until increased } \\
\text { number of summer motorists led cleaning } \\
\text { to begin interfering with driver schedules. } \\
\text { VO notified the DOT of their decision to } \\
\text { cease cleaning the sites. }\end{array}$ & $\begin{array}{l}\text { First three payments to the DOT were late. } \\
\text { The DOT wrote regarding late payments } \\
\text { and motorist complaints regarding empty } \\
\text { machines. }\end{array}$ \\
\hline $\begin{array}{l}\text { Restructuring of VO's accounting system led } \\
\text { to delays in payment to the DOT for the } \\
\text { first } 3 \text { months of the contract. All later } \\
\text { payments were on time. }\end{array}$ & $\begin{array}{l}\text { VO informed the Idaho DOT they would no } \\
\text { longer clean the rest stops as originally } \\
\text { contracted. }\end{array}$ \\
\hline $\begin{array}{l}\text { Immediately upon learning of the } \\
\text { cancellation of the contract, VO attempted } \\
\text { to contact DOT officials. The contract } \\
\text { ended } 4 \text { months from the end of the } 2 \text {-year } \\
\text { trial period. }\end{array}$ & $\begin{array}{l}\text { Following 6-week survey of motorists } \\
\text { traveling the state, the results of which } \\
\text { were quite negative, the DOT began } \\
\text { considering canceling VO contract. At the } \\
\text { same time, the state received lower than } \\
\text { projected royalties. As a result, the } \\
\text { contract was cancelled. }\end{array}$ \\
\hline $\begin{array}{l}\text { Cancellation of the contract led to the } \\
\text { relocation of employees, the restructuring } \\
\text { of VO, and VO being forced to defend its } \\
\text { reputation in a competitive industry. }\end{array}$ & $\begin{array}{l}\text { The State of Idaho is stuck with } 12 \text { empty } \\
\text { vending stations, which cannot be filled } \\
\text { until the dispute is resolved. Motorists are } \\
\text { without vending services. }\end{array}$ \\
\hline
\end{tabular}

to the dispute (e.g., building of the first 12 vending machines, status report of their operation, and notification by defendant that the contract was being revoked), and a description of the main characters, their backgrounds and goals as they related to the dispute. In addition, the plaintiff's attorney offered "reasons" why various characters committed the acts they did, representing the goal-oriented and motivated nature of story composition. For example, the plaintiff's attorney disclosed that the reason the plaintiff pursued the vending contract with the defendant was because it wanted to expand its business in a constricted marketplace.

The defense attorney's narratively structured opening statement mirrored the plaintiff attorney's opening, only told from the defense's perspective. For example, the chronological ordering of events was presented from the defense's perspective, and the backgrounds and goals of characters central to the defense's version of what happened in the dispute were discussed. The defense attorney also offered the 
defense's interpretation of why various events occurred-supplying its own causal connections and goal-directed, motivated explanations for various behaviors. In contrast, the defense attorney's legal-expository-structured opening began with the same statement thanking jurors, followed by a statement that to best render a decision in the dispute, jurors should address the primary legal issues (e.g., cross-claims by the defense and plaintiff regarding breach of contract—did the plaintiff fulfill all its contractual obligations and did the Idaho Department of Transportation cancel the contract in violation of its terms; and damages - did Vending Operations (VO) suffer damages as a result of the cancelled contract). Finally, judicial instructions presented by the judge followed the closing arguments. In addition, the relevant burden of proof applied to the case and the elements the plaintiff must prove by a preponderance of the evidence were presented (i.e., the legal issues). Each element was presented individually, followed by a paragraph summary of the evidence refuting that element. More specifically, jurors were told that it was the plaintiff's responsibility to prove by a preponderance of the evidence that the Idaho DOT was at fault. The defense attorney again stressed that it was the plaintiff, not the defendant, who was responsible for proving their claims. Next, specific issues from the contract were addressed (i.e., how the vending company did not meet the contract). For example, VO did not meet the contract's time schedule for royalty payments, it did not properly maintain and service the vending sites, and the vending stations were not kept clean. The contract also stated that the contract could be voided if there was a material breach and that such a breach occurred when VO did not meet its contractual obligations. Finally, the defense attorney noted that it was VO's responsibility to provide proof that it was damaged by the cancellation of the contract. The attorney concluded by reminding jurors again that the plaintiffs bore the burden of proof and that they should keep the outlined contractual issues in mind as they heard the case. Thus, emphasis during this presentation was placed on the plaintiff's burden of proof, the judicial instructions, and what the evidence would or would not prove.

Narratively structured closing arguments by both plaintiff and defense attorneys mirrored the narrative structures for both parties illustrated above, only with a temporal focus on the past instead of the future (e.g., "the evidence demonstrated" as opposed to "the evidence will demonstrate"). The plaintiff attorney's legal-expository closing argument delineated the legal elements the plaintiff was required to prove and argued why the evidence supported the plaintiff's claim it met its burden of proof in regard to the law governing the case. The defense attorney's legal-expository closing argument delineated the same legal elements, yet argued why the evidence failed to support the plaintiff's claim it met its burden of proof with regard to the governing law.

To avoid quantity confounds, all opening statements and closing arguments were approximately $8 \mathrm{~min}$ in length. Table 1 depicts the combination of plaintiff and defense opening statement and closing argument organizational structures used in the design to create the six experimental conditions. All opening statements and closing arguments were pretested to ensure that participants could identify the underlying organizational format. ${ }^{6}$ ${ }^{6} \mathrm{~A}$ pretest $(n=46)$, which examined four of the six experimental conditions from the $2 \times 3$ design, was
conducted using Conditions One through Four (see Table 1$)$ confirmed that the manipulations were 


\section{Procedure and Instruments}

Upon arrival, subject-jurors completed an informed consent statement followed by an introductory questionnaire assessing basic demographic information and litigation experience. Participants then watched one of the six versions of the stimulus presentation on a color monitor. Each stimulus presentation began with a 5-min orientation by the judge explaining the nature of the dispute, the names of the parties involved, and the terms of the contract pertaining to the dispute. Following this introduction, subjects were exposed to the plaintiff's opening and then one of the two versions of the defense's opening statement. Next, direct and cross-examination of first the two plaintiff's witnesses and then the two defense witnesses were presented, followed by the plaintiff's and then defendant's closing arguments. Video presentations closed with the judge's reading of the jury instructions. After watching the videotape, participants individually completed a second questionnaire analogous to a verdict form. On this questionnaire, they responded "yes" or "no" to four questions constituting the legal elements of the case. Subjects then assigned a percentage of responsibility to the plaintiff and to the defense, totaling $100 \%$. If any responsibility was apportioned to the defendant, participants were told to determine a damage amount to award the plaintiff. Finally, participants ranked the importance of the six primary elements of the presentation (e.g., plaintiff opening, witness examination, defense closing, judicial instructions, etc.). Each experimental session lasted approximately $90 \mathrm{~min}$.

\section{RESULTS}

\section{Statistical Analyses}

Two independent variables-the defense's and plaintiff's organizational strategies-were used in the Analyses of Variance, whereas the percent of responsibility subjects assigned to the defendant and the amount of compensatory damages awarded served as the dependent variables. Analysis of the results focused on identification of significant interaction and main effects for the plaintiff's and defense's organizational strategies. Post hoc contrasts were used to identify significant differences among the three defense organizational strategies.

\section{Main Effects}

Our hypothesis posited that a mixed organizational strategy, with a narrative opening statement and legal-expository closing argument, would be the most effective presentation strategy for the side employing it. Results of a 2 (plaintiff's organizational strategy) $\times 3$ (defense's organizational strategy) factorial ANOVA test showed that subjects' apportionment of responsibility to the defendant was significantly influenced by the plaintiff's organizational strategy, $F(1,240)=4.26$,

working as intendedand determined that the appropriate sample size for the design was a minimum of 125 participants (Cohen, 1977). To review the full results of the pretest and the power analysis, please consult the first author's dissertation results (Spiecker, 1998). 
Table 3. Mean Percentage of Responsibility Apportioned to the Defendant by Organizational Strategy and Average Compensatory Damage Award Apportioned to the Defendant by Defense Organization Strategy ${ }^{a}$

\begin{tabular}{|c|c|c|c|c|c|}
\hline & \multicolumn{5}{|c|}{ Organizational strategy $^{a}$} \\
\hline & \multicolumn{2}{|c|}{ Plaintiff } & \multicolumn{3}{|c|}{ Defense } \\
\hline & $\begin{array}{c}\text { Strict } \\
\text { narrative }\end{array}$ & Mixed & $\begin{array}{c}\text { Strict } \\
\text { narrative }\end{array}$ & $\begin{array}{l}\text { Strict } \\
\text { legal }\end{array}$ & Mixed \\
\hline$N$ & 121 & 125 & 81 & 84 & 81 \\
\hline $\begin{array}{l}\text { Mean percentage of } \\
\text { responsibility apportioned } \\
\text { to the defendant }\end{array}$ & $55.30_{a}$ & $63.60_{b}$ & $74.29 a$ & $49.52_{b}$ & $54.54_{b}$ \\
\hline$S D(\%)$ & 35.68 & 20.33 & 25.84 & 31.84 & 36.36 \\
\hline $\begin{array}{l}\text { Average compensatory } \\
\text { damage award }\end{array}$ & & & $\$ 363,123.91_{a}$ & $\$ 251,520.40_{b}$ & $\$ 262,546.33_{b}$ \\
\hline$S D$ & & & $\$ 258,141.11$ & $\$ 227,395.72$ & $\$ 256,641.50$ \\
\hline
\end{tabular}

${ }^{a}$ Within the plaintiff's and defense's organizational strategy, means with different subscripts differ significantly at $p<.05$. To detect a medium effect size $(f=.24)$ with 246 subjects, according to Cohen (1977) power would equal .98 for the two levels of the plaintiff's organizational strategy and .95 for the three levels of the defense's organizational strategy.

${ }^{b}$ All damage award values were included in the analysis. Median and modes for damage awards for each defense condition are as follows: strict narrative, $M d n=\$ 368,000$, mode $=\$ 250,000$; strict legal, $M d n=$ $\$ 250,000 ;$ mode $=\$ 0.00 ;$ mixed, $M d n=\$ 250,000$, mode $=\$ 0.00$.

$p=.040, \eta^{2}=.016$, as well as the defense's organizational strategy, $F(2,240)=$ $14.09, p<.001, \eta^{2}=.104$. As seen in Table 3 , the mean percentage of responsibility apportioned to the defendant for the two plaintiff's organizational strategies demonstrates that the mixed organizational strategy was more effective for the plaintiff than the strict narrative strategy, consistent with the effect posited in the hypothesis.

Although apportionment of responsibility differed significantly across the three defense organizational strategies, examination of the mean percentage of responsibility apportioned to the defendant across these strategies is inconsistent with the predicted results (see Table 3 ). The results demonstrate that the most effective defense organizational strategy is the strict legal-expository strategy, followed by the mixed strategy. A post hoc Scheffe test conducted on the three defense strategies indicated that the strict narrative strategy was significantly different from the strict legal strategy $(p<.001)$ and the mixed strategy $(p=.001)$. However, the strict legal and mixed strategies did not differ significantly from each other.

Related to subject's compensatory damage awards to the plaintiff, results indicated significant differences across some organizational strategies. Per the verdict form, subjects apportioning responsibility to the defendant were instructed to determine the amount of money (in keeping with the plaintiff's claims) that would fairly and adequately compensate the plaintiff.

Based on the hypothesis, participants hearing the plaintiff's mixed organizational strategy should award more in compensatory damages than subjects hearing the strictly narrative presentation. In addition, subjects hearing the defense's mixed strategy should award lower compensatory damages than subjects hearing a strict narrative or legal presentation. Results of a factorial ANOVA test showed that damage awards differed significantly across the defense organizational strategies, 
$F(2,240)=5.01, p=.007, \eta^{2}=.040$, but not across the plaintiff's organizational strategies, $F(1,240)=0.64, p=.425, \eta^{2}=.003$.

Examination of the average damage awards across the defense organizational strategies indicates these results are inconsistent with the hypothesis. As demonstrated by the average damage awards for the three defense strategies (see Table 3), the most effective defense organizational strategy is the strict legal strategy, followed by the mixed, and then the strict narrative strategy.

Results of the post hoc Scheffe test indicated significant differences between the strict narrative strategy and the other two organizational strategies. The strict narrative strategy was significantly different from the strict legal strategy $(p=.018)$ and the mixed strategy $(p=.037)$. The strict legal and mixed strategies did not differ significantly from each other.

As seen above, the hypothesis was partially supported. Of four factorial ANOVA tests used to examine the hypothesis, only one supported the prediction regarding the plaintiff's organizational strategy. Although two additional ANOVA tests found significant differences due to the defense's organizational strategy, the mean apportionment of responsibility and monetary damage awards for the three defense organizational strategies did not fall in the predicted direction. Examination of these means suggests the defense strict legal strategy was just as effective as the defense mixed organizational strategy.

\section{Interaction Between Plaintiff and Defense Organizational Strategies}

\section{Analysis of Variance}

Next, as there may be some interaction between plaintiff and defense organizational strategies for their opening statements and closing argument, (i.e., a plaintiff's organizational strategy influencing the effectiveness of a defense organizational strategy and vice versa), the interactions effects from the factorial ANOVA tests were examined. Results indicated no significant interaction effects for either apportionment of responsibility, $F(2,240)=0.37, p=.693, \eta^{2}=.003$, or damage awards, $F(2,240)=0.63, p=.535, \eta^{2}=.005$. The interaction effect for subjects' summated confidence scale scores was also nonsignificant, $F(2,240)=1.11, p=.330, \eta^{2}=.008$.

\section{DISCUSSION}

\section{Hypothesis}

Results found that a mixed organizational strategy (narrative opening/legalexpository closing) was more effective than the strict narrative strategy for the plaintiff in terms of subject-jurors' apportionment of responsibility verdicts. However, although subjects exposed to the plaintiff's mixed strategy awarded slightly more money to the plaintiff $(M=\$ 303,454.30, S D=\$ 249,102.60)$ than subjects exposed to the strict narrative strategy $(M=\$ 281,784.40, S D=\$ 254,582.00)$, this difference was not significant. 
Legal and communication scholars theorize an opening statement functions best when enabling jurors to create a schema within which to organize subsequent information and a closing argument functions best when synthesizing evidence, legal argument, and decision rules for jurors (Matlon, 1993; Moore, 1989; Pyszczynski \& Wrightsman, 1981). Thus, by organizing the information presented around the legal elements appearing on the verdict form, defining and emphasizing terms included in the judicial instructions, and demonstrating how the evidence supported the plaintiff's interpretation of those instructions, the plaintiff's legal-expository closing argument may have better familiarized jurors with the context in which they were required to make a decision. This structure may also have given the impression that the law supported the plaintiff's interpretation of the evidence.

Unfortunately, the study's design does not allow us to determine if the plaintiff's mixed organizational strategy was more effective than the strict narrative strategy because the legal-expository structure in the mixed strategy better met the functions of a closing argument. In this investigation, measurement was not included to determine if subjects actually used the opening statement and closing argument for different purposes, creating and using schematic frameworks based on the opening statement, and synthesizing trial information following the closing argument. However, it is reasonable to conclude the plaintiff's legal-expository organizational strategy met the purposes of a closing argument more aptly than did the plaintiff's narrative structure.

The hypothesis was supported with regard to the plaintiff's organizational strategy and subject-jurors' apportionment of responsibility, but the results do not support the hypothesis regarding the effects of the defense's organizational strategy. Although the defense mixed strategy was significantly more effective than the defense strict narrative strategy with regard to apportionment and monetary awards, there was not a significant difference between the defense mixed and strict legal strategies. In fact, the average apportionment of responsibility to the defendant and the average compensatory award to the plaintiff were both slightly lower in the defense strict legal strategy than in the defense mixed organizational strategy (see Table 3).

However, the function of a closing argument may explain not only why the plaintiff's mixed organizational strategy was more effective than the strict narrative strategy, but also why the defense mixed and strict legal strategies were significantly more effective than the defense strict narrative strategy. In both the defense strict legal and mixed strategies, the closing argument was organized around the legalexpository structure, whereas the defense strict narrative strategy employed a narratively organized closing argument. As with the plaintiff's legal-expository closing argument in the plaintiff's mixed strategy, it is probable the legal-expository closing arguments in the defense mixed and strict legal strategies best met the synthesis and decision-criteria establishment functions of a closing argument. The results suggest a legal-expository structure is better suited for a closing argument than is a narrative structure, and that using an organizational structure designed to meet the function of the presentation is more effective than mechanically applying a narrative structure regardless of the presentation's conceptual purpose.

This investigation supports the belief that jurors construct narratives as a way of organizing and understanding trial-related information, and past research (Devine 
\& Ostrom, 1985; Pennington \& Hastie, 1986, 1988, 1992) indicates jurors' story construction is facilitated by presenting information to jurors in narrative form The results of this investigation add to that understanding by suggesting that telling a story is not enough; it is also important to show jurors what to do with the story they have created. A legal-expository structure explicitly demonstrates how jurors' impressions and mental constructs regarding the dispute translate into a verdict. Presented with an explicit explanation of how their story is consistent with the instructions and legal elements they are told to follow, jurors are given a guideline and justification for returning a specific verdict. This organization is especially important as jurors are instructed by the court to render their verdict based on the evidence presented and the law governing the case. In addition to warranting a resolution to the story in the form of a verdict, the legal-expository organizational structure also makes jurors' jobs easier, as the connection between narrative reasoning and legal decision is made for them.

Additional analysis supports the conclusion that the significant effectiveness of the defense mixed and strict legal strategies over the defense strict narrative strategy is due to the influence of the legal-expository closing argument. Subjects were instructed on the Exit Questionnaire to rank-order six aspects of the stimulus in terms of how influential they perceived each presentation to be in their decision-making process. Results from analysis of subjects' rankings of the presentation most influential to their decision found a significant defense organizational strategy effect. Specifically, results of a 3 (defense organizational strategy) $\times 6$ (presentation) chi-square analysis found the defense organizational strategy significantly influenced subjects' rankings of the most influential presentation, $\chi^{2}(10, N=242)=22.29, p=.014$. Additional analysis of the mean ratings for each presentation by defense organizational strategy indicated that the difference lies in importance ratings for the defense closing argument, $F(2,243)=12.50, p<.001, \eta^{2}=.092$. As seen in Table 4 , subjects exposed to the defense strict legal or mixed organizational strategy were more likely than subjects hearing a defense strict narrative strategy to rate the defense's closing argument as the most influential presentation.

Although the efficacy of the legal-expository closing argument explains why both the defense strict legal and mixed strategies were more effective than the defense strict narrative strategy, why was the defense strict legal strategy just as effective as the defense mixed strategy? Structuring the opening statement around a story explaining the dispute from the defense's perspective did not afford the defense a strategic advantage as was predicted. Omitting the presentation of any narrative and focusing solely on a legal-expository format was just as effective for the defense as using a mix of organizational strategies. It is likely this outcome resulted from the fact the defense opening statement, regardless of organizational structure, followed the plaintiff's narrative opening statement. As such, the plaintiff's narrative opening established a sufficient context for the dispute to provide jurors with enough information to draw on a schematic framework and thus organize subsequent information. Freed from the need to establish some conceptual framework, explaining how the plaintiff's story could be reinterpreted to support the legal elements and judicial instructions in a manner favorable to the defense was just as effective as presenting jurors with an alternative, defense-oriented narrative explanation. 
Table 4. Subjects' Rankings of the Influence of Presentation Components by Defense Organizational Strategy

\begin{tabular}{|c|c|c|c|}
\hline \multirow[b]{2}{*}{ Presentation } & \multicolumn{3}{|c|}{ Defense organizational strategy mean rating } \\
\hline & Strict narrative & Strict legal & Mixed \\
\hline Plaintiff's opening statement & 2.98 & 3.36 & 3.53 \\
\hline Defense opening statement & 4.13 & 3.99 & 4.16 \\
\hline Witness examination & 2.31 & 2.84 & 2.45 \\
\hline Plaintiff's closing argument & 3.59 & 3.79 & 3.59 \\
\hline Defense closing argument & $4.71_{a}$ & $3.85_{b}$ & $3.44_{b}$ \\
\hline Judicial instructions & 4.79 & 4.36 & 4.45 \\
\hline Mean ranking $^{b}$ & 152.80 & 116.45 & 101.51 \\
\hline$N$ & 81 & 83 & 80 \\
\hline
\end{tabular}

Note. A ranking of $1=$ most influential presentation and $6=$ least influential. The lower the ranking the more influential the presentation. Means with different subscripts differ significantly at $p<.001$.

${ }^{a}$ Results of one-way ANOVAs conducted on the mean ranking of each presentation by each defense condition: plaintiff's opening, $F(2,243)=1.56, p>.05, \eta^{2}=$ .013 ; defense Opening, $F(2,243)=0.246, p>.05, \eta^{2}=.002$; witness examination, $F(2,243)=2.14, p>.05, \eta^{2}=.017$; plaintiff's closing, $F(2,243)=0.343, p>.05$, $\eta^{2}=.003$; defense closing, $F(2,243)=12.50, p<.001, \eta^{2}=.093$; judicial instructions, $F(2,243)=1.88, p>.05, \eta^{2}=.015$.

${ }^{b} \chi^{2}(10, N=242)=22.29, p=.014$.

In summary, it appears strategic for both the plaintiff and defense to organize their closing arguments around a legal-expository organizational structure. In addition, the results suggest that it may not be necessary for the defense to present a narrative opening when the plaintiff has already presented a story. Pennington and Hastie's Story Model and the popularized concept of legal storytelling both suggest that a narrative organizational structure is inherently the most effective presentation format. Yet the general prescription advocating narrative presentations fails to account for the differential functions of opening statements and closing arguments or for the placement of a defense opening statement uniformly subsequent to either the plaintiff's opening or case-in-chief. The results of this investigation qualify the storytelling technique's prescription by demonstrating that an alternative, nonnarrative organizational structure exists that, under certain conditions, can be even more effective than the narrative presentation format.

\section{Interaction Between Plaintiff and Defense Organizational Strategies}

The results indicated that the parties' organizational strategies do not interact to influence presentation effectiveness, subject-jurors' perceived presentation influence and importance, or subject-juror confidence. As seen earlier, results of tests used to examine the possibility of an interaction effect for plaintiff and defense organizational strategies failed to find a significant interaction effect.

Pragmatically, it is advantageous that plaintiff and defense organizational strategies do not interact to influence juror decision-making. It is difficult for a plaintiff's attorney to anticipate what organizational strategy the defense will employ and for a defense attorney to make adjustments to a planned organizational strategy during 
trial in response to the plaintiff's strategy. Thus, lack of a significant interaction effect is practically appealing. At the same time, however, until additional research is conducted that manipulates a plaintiff's strict legal-expository strategy, it is imprudent to conclude that the plaintiff and defense's organizational strategies necessarily operate independently of each other.

\section{CONCLUSION}

\section{Implications}

As noted earlier, there is a widespread belief in the legal community that attorneys should use a narrative format in their opening and closing statements. However, little empirical research has tested this belief. Although there are certainly a variety of factors that may influence jurors during the course of a trial, this study provides initial evidence that an attorney's presentational organizational strategy as employed in opening statements and closing arguments influences jurors' verdicts, affecting apportionment of responsibility and monetary damage awards. In addition, both plaintiff and defense advocates can maximize the effectiveness of their presentations by structuring at least the closing argument around a legal-expository format, delineating the legal elements and judicial instructions governing the case, and interpreting how the evidence meets these criteria when used by the plaintiff or fails to meet these criteria when employed by the defense. It also appears that a strict legal-expository organizational strategy is just as effective as a mixed strategy (narrative opening/legal-expository closing) for the defense.

Therefore, although faced with theoretical and practical endorsement of the storytelling technique, litigators should not feel compelled to follow the storytelling trend and structure all presentations narratively. Although a narrative structure can be effective, it is best to evaluate the presentation's purpose and choose an organizational strategy that maximizes the purposes of the presentation, rather than mechanically applying a specific format, whether narrative or legal-expository.

\section{Limitations}

Several potential limitations to this study should be noted. First, common limitations associated with this type of study include the fact that videotaped presentations do not simulate an actual trial environment and that the effect of group dynamics upon juror verdicts was not assessed. In addition, the subject population was not closely representative of a typical jury. However, the focus of this investigation was on the influence of organizational structure on decision-making and reasoning, not on a possible interaction between juror demographics and the influence of organizational strategy. Finally, the length of the stimulus presentation may have enhanced the influence of organizational structure. Perhaps when embedded within an actual trial with direct and cross-examination from multiple witnesses, the influence of organizational structure may be less prominent.

Finally, and most importantly, because the stimulus material may have interacted with organizational structure, the results of this investigation must be generalized 
with caution. Until additional research is conducted with alternative stimulus materials and a variety of cases and judicial instructions, we cannot be sure that the conclusions drawn in regard to the effectiveness of various organizational strategies apply in other case contexts. For example, results of research by Voss, Wiley, and Sandak (1999) and Voss and Van Dyke (2001) suggests that when jurors are faced with "uncertain" or ambiguous evidence that the overall quality of a narrative may affect juror's decisions, at least in a criminal context. Specifically, narrative quality appears to play a greater role when evidence is inconclusive. In the present study, the evidence presented was, in several areas, ambiguous. For example, there was some uncertainty whether the contract actually included a stipulation that VO was to keep the vending sites clean or whether VO made a concerted effort to contact the Idaho DOT after they were notified that the contract would be cancelled. Thus, characteristics of the message stimulus itself may cause or contribute to the results, weakening or invalidating the connection between the manipulation and the scientific finding.

In the context of this investigation, there are two primary aspects of the "message" that are of concern-the case used as the stimulus and the definition and enactment of the various organizational strategies used in the design. It is possible the results of this investigation may not apply to other cases, and that advocates and other researchers may define the organizational strategies slightly differently than the working definitions used in this investigation. Further, the many categories of legal cases, such as medical malpractice, contract, or environmental contamination cases, illustrate that the context framing one legal dispute does not necessarily apply to another. Moreover, even within case categories, different parties, evidence, advocates, judicial instructions, venues, and juries, limit the generalizability of the results of one case to another case within the same category. To better control for message effects in legal communication research, it will be important to devote the necessary resources to include multiple messages in research designs, select messages that best generalize across cases, and use multiple methods of measurement when studying the influence of message variables on juror behavior and trial outcomes.

\section{Directions for Future Research}

This investigation offers several directions for future research. First, the effects of organizational strategy should be examined with other stimulus cases representing other case categories. Second, future experimental designs should be tested that manipulate the effect of a plaintiff's strict legal strategy or an alternative, nonnarrative organizational format in the plaintiff's opening statement. This design would test for the effectiveness of both a plaintiff's strict narrative strategy and the impact of a nonnarrative plaintiff's opening statement on the defense's organizational strategy. Finally, the strict legal-expository strategy manipulated in the current study represents a modified version of the trial advocacy technique of presenting a "strict defense." A defense team presenting a strict defense may decide strategically to refrain from having defense witnesses reinterpret the evidence to favor the defense or opt not to call key defense witnesses altogether. In this context, a strict defense becomes more of an overall case strategy than an organizational strategy. It would be 
valuable to examine the relationship between a strict legal-expository organizational strategy and a strict defense case strategy.

\section{REFERENCES}

Bennett, W., \& Feldman, M. (1981). Reconstructing reality in the courtroom justice and judgment in American culture. New Brunswick, NJ: Rutgers University Press.

Bower, G. H., Black, J. B., \& Turner, T. J. (1979). Scripts in memory for text. Cognitive Psychology, 11, $177-220$.

Brewer, W. F., \& Liechtenstein, E. H. (1981). Event schemas, story schemas, and story grammars. In J. Long \& A. D. Baddeley (Eds.), Attention and performance IX (pp. 363-379). Hillsdale, NJ: Erlbaum.

Cohen, J. (1977). Statistical power analysis for the behavioral sciences. New York: Academic Press.

Cohen, A. D., \& Graesser, A. C. (1980). The influence of advanced outlines on the free recall of prose. Psychonomic Society, 15, 348-350.

Connolly, P. R. (1982). Persuasion in the closing argument: The defendant's approach. In G. W. Holmes (Ed.), Opening statements and closing arguments (pp. 159-164). Ann Arbor, MI: The Institute of Continuing Legal Education.

Devine, P. G., \& Ostrom, T. M. (1985). Cognitive mediation of inconsistency discounting. Journal of Personality and Social Psychology, 49, 5-21.

Feigenson, N. (1995). The rhetoric of torts: How advocates help jurors think about causation, reasonableness, and responsibility. Hastings Law Journal, 47, 61-165.

Graesser, A. C. (1981). Prose comprehension beyond the word. New York: Springer.

Herman, R. (1993). Telling the story: Devices and techniques. Trial Lawyers Quarterly, 23, 47-54.

Jackson, B. A. (1991). Narrative models in legal proof. In D. R. Papke (Ed.), Narrative and the legal discourse: A reader in storytelling and the law (pp. 158-178). Liverpool, U.K.: Deborah Charles.

Kadoch, L. C. (2000). Seduced by narrative: Persuasion in the courtroom. Drake Law Review, 49, 71-124.

Larson, J. E. (2000). "A good story" and the "real story.” The John Marshall Law Review, 34, 181-192.

Lempert, R. (1991). Telling tales in court: Trial procedure and the story model. Cardozo Law Review, 13, 559-573.

Lubet, S. (1989). Vending Operator, Incorporated v. Nita Department of Transportation problems and case file. Notre Dame, IN: National Institute for Trial Advocacy.

Lubet, S. (1993). Modern trial advocacy: Analysis and practice. Notre Dame, IN: National Institute for Trial Advocacy.

Mandler, J. M. (1984). Stories, scripts, and scenes: Aspects of schema theory. Hillsdale, NJ: Erlbaum.

Mandler, J. M., \& Johnson, N. S. (1977). Remembrance of things past: Story structure and recall. Cognitive Psychology, 9, 111-151.

Manzo, J. F. (1994). "You wouldn't take a 7 year-old and ask him all these questions": Jurors' use of practical reasoning in supporting their arguments. Law and Social Inquiry, 19, 639-663.

Matlon, R. J. (1988). Communication in the legal process. New York: Holt, Rinehart and Winston.

Matlon, R. J. (1993). Opening statements/closing arguments. San Anselma, CA: Stuart Allen Books.

Mauet, T. A. (1992). Fundamentals of trial techniques. Boston: Little Brown.

McCullough, G. (1991). Juror decisions as a function of text format of opening statements and closing arguments. Unpublished doctoral dissertation, The University of Kansas.

Miller, B. (1994). Give them back their lives: Recognizing client narrative in case theory. Michigan Law Review, 93, 485-576.

Montz, C. L. (2001). Why lawyers continue to cross the line in closing argument: An examination of federal and state cases. Ohio Northern Law Review, 28, 67-131.

Moore, A. (1989). Trial by schema: Cognitive filters in the courtroom. UCLA Law Review, 37, 273-340.

Ogborn, M. (1995). Storytelling throughout trial. Trial, 31, 63-65.

Ohlbaum, E. D. (1993). Basic instinct: Case theory and courtroom performance. Temple Law Review, 66, $1-113$.

Oliver, E. (1994). Embodying the story. Trial Diplomacy Journal, 17, 177-183.

Pennington, N., \& Hastie, R. (1981). Juror decision-making models: The generalization gap. Psychological Bulletin, 89(2), 246-287.

Pennington, N., \& Hastie, R. (1986). Evidence evaluation in complex decision making. Journal of Personality and Social Psychology, 51, 242-258.

Pennington, N., \& Hastie, R. (1988). Explanation-based decision making: Effects of memory structure on judgment. Journal of Experimental Psychology, 14(3), 521-533. 
Pennington, N., \& Hastie, R. (1992). Explaining the evidence: Tests of the story model for juror decision making. Journal of Personality and Social Psychology, 62(2), 189-206.

Powell, G. R. (2001). Opening statements: The art of storytelling. Stetson Law Review, 31, 89-105.

Pyszczynski, T., \& Wrightsman, L. S. (1981). The effects of opening statements on mock jurors' verdicts in a simulated criminal trial. Journal of Applied Social Psychology, 11, 301-313.

Rieke, R. D., \& Stutman, R. K. (1990). Communication in legal advocacy. Columbia, SC: University of South Carolina Press.

Schum, D. (1993). Argument structuring and evidence evaluation. In R. Hastie (Ed.), Inside the juror: The psychology of juror decision making (pp. 175-191). Cambridge, UK: Cambridge University Press.

Sherwin, R. K. (1994). Law frames: Historical truth and narrative necessity in a criminal case. Stanford Law Review, 47, 39-83.

Smith, V. L. (1991). Prototypes in the courtroom: Lay representations of legal concepts. Journal of Personality and Social Psychology, 61, 857-872.

Smith, V. L. (1993). When prior knowledge and law collide: Helping jurors use thelaw. Law and Human Behavior, 17, 507-536.

Spence, G. (1995). Let me tell you a story. Trial, 31, 73-79.

Spiecker, S. C. (1998). The influence of opening statement/closing argument organizational strategy on juror reasoning and decision-making. Dissertation Abstracts International, 59(05), 1399. (UMI No. AAT9833846)

Stein, N. L., \& Policastro, M. (1984). The concept of a story: A comparison between children's and teacher's viewpoints. In H. Mandel, N. L. Stein, \& T. Trabasso (Eds.), Learning and comprehension of text (pp. 113-155). Hillsdale, NJ: Erlbaum.

Stein, N. L., \& Trabasso, T. (1982). What's in a story? An approach to comprehension and instruction. In R. Glaser (Ed.), Advances in instructional psychology (pp. 213-267) (Vol. 2). Hillsdale, NJ: Erlbaum.

Trabasso, T., van den Broek, P., \& Suh, S. (1989). Logical necessity and transitivity of causal relations. Discourse Processes, 12, 1-25.

Voss, J. F., \& Van Dyke, J. A. (2001). Narrative structure, information certainty, emotional, content, and gender as factors in a pseudo jury decision-making task. Discourse Processes, 32, 215-243.

Voss, J. F., Wiley, J., \& Sandak, R. (1999). On the use of narrative as argument. In S. R. Goldman, A. C. Graesser, \& P. van den Broek (Eds.), Narriative, comprehension, causality, and coherence: Essays in honor of Tom Trabasso (pp. 235-252). Mahwah, NJ: Erlbaum. 